University for Business and Technology in Kosovo

UBT Knowledge Center

UBT International Conference

2013 UBT International Conference

Nov 2nd, 11:30 AM - 11:45 AM

\title{
Inflation targeting and its effects on the inflation: Albanian case
}

Oltjana Zoto

European University of Tirana, oltjanazoto@yahoo.com

Arbri Agalliu

European University of Tirana, arbri.agalliu@uet.edu.al

Follow this and additional works at: https://knowledgecenter.ubt-uni.net/conference

Part of the Business Commons

\section{Recommended Citation}

Zoto, Oltjana and Agalliu, Arbri, "Inflation targeting and its effects on the inflation: Albanian case" (2013). UBT International Conference. 35.

https://knowledgecenter.ubt-uni.net/conference/2013/all-events/35

This Event is brought to you for free and open access by the Publication and Journals at UBT Knowledge Center. It has been accepted for inclusion in UBT International Conference by an authorized administrator of UBT Knowledge Center. For more information, please contact knowledge.center@ubt-uni.net. 


\title{
Inflation targeting and its effects on the inflation: Albanian case
}

\author{
Oltjana Zoto ${ }^{1}$, Arbri Agalliu ${ }^{2}$ \\ European University of Tirana \\ oltjanazoto@yahoo.com²_arbri.agalliu@uet.edu.al ${ }^{2}$
}

\begin{abstract}
Transformation from a centrally planned economy to a market economy was accompanied by a number of reforms such as the efforts to fully liberalize prices and the creation of a two-level banking system. To achieve this goal there was the need to include the monetary policy as one of the main macroeconomic policies. The law on "the Bank of Albania" defined the competence of BoA to draft and implement the monetary policy by keeping the price stability as principal goal. There are several monetary policies strategies or regimen to achieve the prices stability such as: targeting of the monetary mass, targeting of the inflation, and monetary policy with implicit nominal anchor. The analysis will focus on the Inflation Targeting regimen, its progress over the years starting from the period when it began to be applied and the effects of this regimen to the inflation before and after the economy crisis.
\end{abstract}

Keywor ds: Inflation targeting, inflation, monetary policy, strategy.

\section{Introduction}

Inflation is a phenomenon that occurs when the general level of prices and costs in the economy increase. The price increase is not necessarily uniform for all products. For measuring the inflation in Albania the Consumer Price Index plays a crucial role. The Consumer price Index is the measuring of the cost of a representative basket of goods and services. The question that rises in this case is: what are the factors that cause the inflation? These are different factors among which are: a. the high level of demand for money (inflation caused by demand) $b$. inflation caused by supply. It should be noted that even in cases where we are in terms of a balance between supply and demand not necessarily the level of inflation is zero or low. An important role is also played by inflationary expectations. Inflationary expectations are important for the behavior of wages and prices in the economy. Thus if in the future inflation is expected to rise, then employees will increase pressure for the wage increase. What determines the extent or inflationary expectations rate? The answer to this question depends on monetary policy and the trust that individuals have on the Central Bank and the government. The function of monetary policy is the management of the money quantity in the economy and of the interest rates aiming at the general price level stability, economic growth and financial stability. Inflation is often identified as being the primary objective of the monetary policy, by making it the only legal objective of a bigger number of banks. Meanwhile, besides this objective, some countries have included in their laws on the Central Bank objectives like the support to the economic growth or keeping the financial stability. These two systems are founded on different economic theories and principles, by identifying the differences on the Classic and Keynes school. Classical School sees the economy with full employment and the money as a medium of exchange. In this context, the monetary policy affects only the value of money, namely the rate of inflation. Its use for other purposes would be wrong. According to this line of thought, the only objective of monetary policy should be the control of inflation. According to Friedman inflation is always and everywhere a monetary phenomenon. The Keynesians challenged the assumption that the economy always uses its maximumpotential by creating the concept of insufficient domestic demand to generate full employment in certain periods. In this context, monetary and fiscal policy can and should be used in a countercyclical manner in order to keep the economy near its potential. In the Phillips Curve theory there is an inversed relation between unemployment rate and inflation rate. Even Keynesians accept the fact that monetary policy cannot be used as an active instrument to generate economic growth in the long run. Their emphasis was on the potential role of monetary policy to mitigate the impact of short-term shocks on the economic activity. Keynesianism was the dominant current in the period immediately after the Second World War. However, the application of his suggestions in politics was relatively limited by the existence of a fixed 
exchange rate. The collapse of the Bretton-Woods system in 1973 and the loss of fixed convertibility of currencies to the dollar and gold served as a laboratory for testing a variety of monetary regimes. The experience showed that countries with lower inflation had a better performance in terms of faster economic growth and higher employment. Economic literature turned its focus on explaining these phenomena. The theory of rational expectations, and especially the work of Lucas (1972) and Kydland and Prescott (1977), suggested a plausible theory which explains the inability to use the inverse relationship between economic activity and inflation. This theory is called the theory of inconsistency in time of monetary policy. In its most simple version, it predicts that monetary policy can be effective in stimulating economic activity only if it generates surprise to the market, when economic agents do not expect the monetary stimulus. In these circumstances, and given the existence of fixed contracts in nominal terms, money supply growth leads to increased purchasing power and increased production. However, the existence of rational expectations of economic agents make them understand the incentive tools that Central Banks use and try to prevent it through higher contracts in nominal terms. In these circumstances, the existence of irregularities in the design of monetary policy produces inflation and inflationary expectations, without benefits for the economic growth.

Later, the theory of rational expectations is analyzed in the context of the relationship between rules and irregularity, or the ratio between credibility versus flexibility in the monetary policy. A monetary policy which would be totally spontaneous (irregular) would produce inflation without additional economic growth, while monetary policy based entirely on the rules would not be able to respond to economic shocks or unexpected events.

The main consequence of these theories is the placement of price stability in the exclusive focus of the work of most of Central Banks.

Although these theories do not deny the existence of connections between short-term unemployment rate and the inflation, their use from monetary policy is impossible because the easing ofbusiness cycles may be somewhat a legitimate target for central banks with stabilized reputation and operating in economies with developed financial markets and functional transmission mechanisms while mitigating business cycles would be a relatively unrealistic target for central banks in transition countries, which operate in absence of information and through dysfunctional transmission mechanisms, characterized by uncertainty and significant time delays.

The primary goal of monetary policy of most central banks is the stability of prices but there are other objectives related to employment, economic growth, financial stability, interest rates and currency exchange rates. High unemployment leads to poverty and absolute decrease production. So employment is desirable. The question is: how high should it be? Should be at such level that would mean zero unemployment? Unemployment should be close but not zero, because a low level of unemployment is of benefit to the economy. Employment target otherwise called "full employment" means an unemployment rate close to but above zero and corresponds to labor's equation between supply and demand. Unemployment rate corresponding to "full employment" is not constant and is currently estimated in the range of 4.5 to $6 \%$. The purpose (or objective) of high economic growth is as sociated with high levels of employment. When employment is high, companies invest to increase the capital stock because it is more efficient to invest in capital when the workforce has a relatively high cost. This brings greater economic growth. Policies that encourage investment and increase public savings through lower tax are called supply policies and deal precisely with the objective of high economic growth. Financial stability is also an important objective given that the financial system is important for lending to the economy. The interest rates stability is related to financial stability. When interest rates rise too much, they reduce the value of the investment portfolio of various financial institutions and this puts them in trouble, which can cause their bankruptcy. Exchange rate stability has to do with the country's competitiveness in the international market. A depreciation of the local currency against the currencies of other countries brings temporary increased competitiveness of goods and services produced in the country against foreign goods. On the other hand it gives rise to inflation because imported goods and services become more expensive. 


\section{Literature review}

Theoretically there are several strategies related to the monetary policies like: a) targeting of the monetary mass, b) targeting of the inflation, and c) monetary policy with implicit nominal anchor.

\subsection{Targeting of the monetary mass}

If Central Bank pursues this strategy, it declares that it will achieve a certain objective expressed in terms of money mass growth. Pursuing this strategy is thought to have several advantages. Firstly, the central bank under this regime is publicly accountable when there are deviations fromthe target because everyone can calculate the money mass growth. Secondly under this regime the position of central bank' policy makers about inflation seems clear. On the other hand, there are disadvantages. In order for this regime to function in economy should exist a link (or connection) between money mass and inflation (or nominal income). If the connection does not exist or is weak then the achievement of the money mass objective by the central bank does not mean that the strategic objective will be achieved as well, namely the price stability ( or low inflation ). On the other hand monetary targeting (and central bank that applies it) becomes untrustworthy for the public, which "acts on its own", therefore the inflation expectations go outside the $2-4 \%$ frame.

\subsubsection{Money Mass Targeting in USA; Japan and Germany}

Monetary targeting strategy was suggested by M. Friedman, given the monetarist view that a controlled growth of money will produce as a result a controlled inflation. In ' 70 s some countries adopted the strategy of monetary mass targeting.

In the USA the experience showed that it was difficult to achieve the objective of increasing the monetary mass control (in this case the measure M1) because during this period there were shocks coming from innovations and liberalization in financial markets.

A more compelling reas on for the failure of M1 growth target was that the Fed's real intention was to use interest rates to eradicate inflation rather than achieving the objective of M1. It is known that when one's objective is the monetary mass he loses control of interest rates and vice versa.

In Japan, the M2 monetary targeting began after the oil price shock in 1973. This shock led to high inflation. Japan succeeded because the monetary targeting was achieved with smaller fluctuations than in the USA, and this led to lower inflation and less volatile product.

The later experience of the years 1987-1989, was not good for the Japanese economy, because the liberalization of financial markets, the concerns about the yen's strengthening against the dollar led to a M2 greater increase than the target.

After 1989, the monetary mass was limited more than it should. This was the opposite direction. According to many economists, that limitation brought stagnation and deflation in the Japanese economy.

In Germany, was targeted a narrower mass to M3. Monetary targeting strategy was implemented with flexibility and brought very good results, i.e. low inflation in the long term as well as short-term stability of the exchange rate and production.

\subsection{Inflation targeting}

Since monetary targeting strategy was associated with the problem of a clear link between monetary mass and inflation, many countries began to adopt inflation targeting strategy to achieve stability of the general price level. This regime determines the level of inflation and monetary policy through its instruments intends to guide the economy to converge to this level.

Interest rates are determined in such a way that aggregate demand answers to the determined level of inflation. Inflation targeting implies fulfillment of certain preconditions. They are: public communication of the medium-term inflation target, price stability has to be the primary objective of the central bank and the latter's commitment to do everything possible to achieve this objective, 
monetary policy decisions are based on all economic variables not only on the monetary mass, increased central bank's transparency and increased accountability of the central bank.

\subsubsection{Inflation targeting in New Zealand, Canada and UK}

In New Zealand, was implemented for the first time the inflation targeting regime. Preconditions that were met were: definition of price stability as the primary goal of monetary policy, declaring independence of the central bank from other institutions, the definition of a medium-term inflation target of $3-5 \%$ and the central bank's accountability to Parliament. As a result, from about $5 \%$ inflation dropped to less than $3 \%$. Initially the cost was a deep recession with high unemployment. After 1992, inflation remained under control and the economy expanded with a production growth of 5\% annually.

Even in Canada the UK, before the adoption of inflation targeting regime, there were pre -conditions similar to those of New Zealand. Results achieved and costs were similar between these countries.

\subsubsection{Advantages of Inflation Targeting}

In the first place, to achieve the inflation target the Central Bank uses all the available information, not only the monetary developments like in the case of monetary mass targeting. Also, the connection money-inflation is not necessary for inflation targeting to work.

In the second place, the regime is easily understood by public through the communication of mediumterm inflation target.

In the third place, the regime means a bigger public accountability of the Central Bank.

In the fourth place, is greatly reduced the possibility of the central bank to become prey to pressures to pursue expansionary policies and as a consequence of to get stuck in the trap of time inconsistency in monetary policy.

In the fifth place, increased transparency and communication with the public brings clarity to the public but also to other institutions for what it does and what is likely to do the central bank.

\subsubsection{Disavantages of inflation targeting}

The first problem is the late signalizing to the market about monetary policy position because the central bank has not enough strong control over the inflation as it has over the monetary mass, and because it takes time for monetary policy to act on inflation. The second problem has to do with regime's the lack of elasticity. So the criticism is that there is only inflation targeting following and there cannot take measures in order to react to unforecasted situations. The third problem has to do with the claim that this regime is likely to increase employment fluctuations and it lowers economic growth. It is true that with the adoption of this regime was observed lowering of economic growth rhythms, but it was only for the phase of inflation reducing. Further experience showed (New Zealand, Canada) that economic growth was the same at least as before the regime. Under this regime policymakers are aware of the fluctuations of production because medium term inflation target is clearly above zero. This implies measures by central banks in case ofdeflation danger(deflation is the enemy of economic growth and employment in the short run).

\subsection{Monetary policy with an implicit nominal anchor}

U.S. Central Bank (Fed) has a slightly different strategy from the two regimes above. This strategy is based on that monetary policy should have two important features: should be based on forecasts of future inflationary developments and prevent inflation risk.

These two features are necessary for the fact that monetary policy decisions take time to materialize (Friedman) in the economy. If the central bank waits until appears the high inflation in the economy the battle is lost without beginning, because every decision today will affect inflation coming one year later and not the high inflation today.

Fed policy for the discreet use of an implicit nominal anchor can be best described by the words "leave everything else, but do not ask anyone but act today if higher inflation is predicted in the future." 
Advantages of Monetary Policy with an Implicit nominal anchor:

1. to achieve success does not have to rely on money-inflation link.

2. in monetary policy formulation is used all available information,

3. the motto "leave everything else, do not ask anyone but act today if high inflation is forecasted in the future" is less likely to fall into the trap of time inconsistency in monetary policy.

Disadvantaged of Monetary Policy with an Implicit Nominal Anchor

1. The lack of transparency makes Fed less accountable and the public will have to play the role of the player that tries to find the rate of the inflation and of the production in the future.

2. The dependence of monetary policy by the personalities managing Fed.

3. Monetary policy affects the whole society but it is drafted by an elite that is not much accountable to the public in the event of failure.

\section{Monetary targeting in Albania}

When inflation is under control, the informative role of the monetary aggregates increases ate the same level that the relative "noises" of the shocks of money speed increase. According to them, this might be a very significant reason why the industrialized countries and several other ones under development did not support the monetary control during the period of the prices stability. The speed change of money circulation might be attributed mostly to the instable request for money which has increased particularly with the advancements and the structural changes of the financial systems. The Bank of Albania has had several objectives during these years of transition, but the main objective ascertained by law is the preservation of the general stability of the prices. The public announcement was done making known the annual increase norm of the aggregate indicator M3.

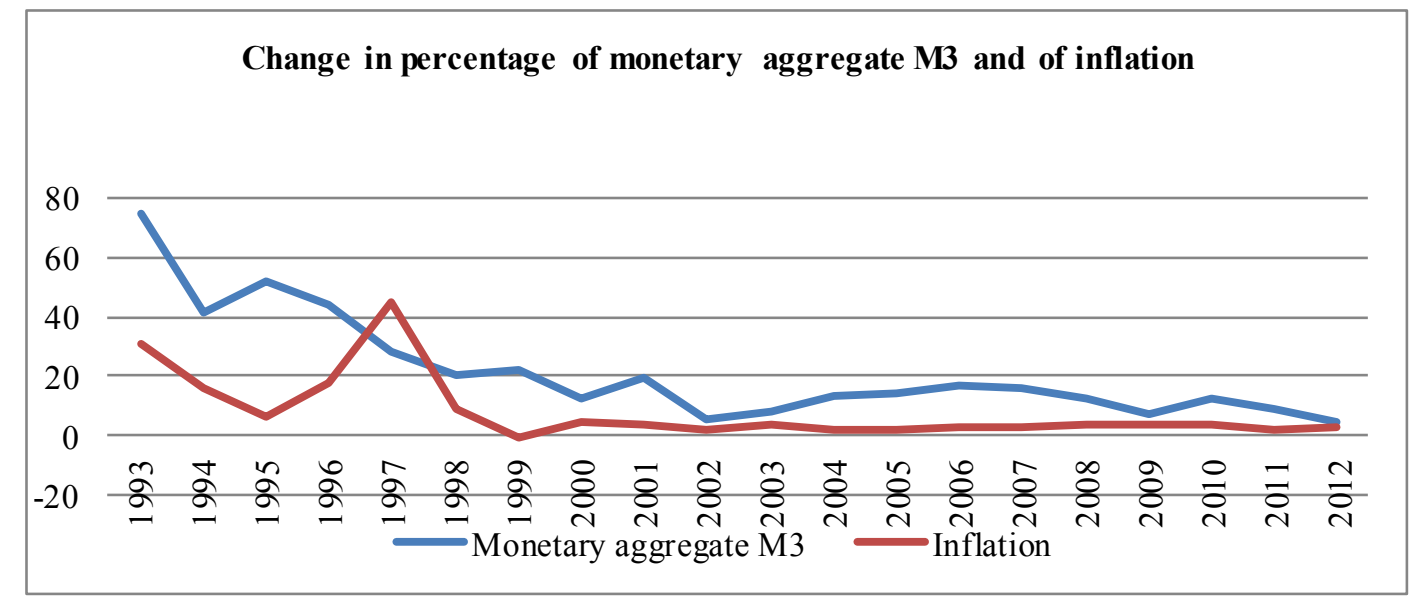

Fig.1: Change in \% of monetary aggregate and of inflation

\section{Source: Bank of Albania}

The analysis of the data provided by the table helps us to arrive at some important conclusions: the norms of the aggregate M3 change have been more fluctuating than the ones of the inflation change. This feature makes it more difficult for the public to understand the main objective of the Bank of Albania based only on the norms of the monetary change M3. This way it is proved that inflation, especially for the developing economies, is not influenced only by the norm of the M3 increase, but even by other factors such as: the fluctuations of the exchange rate, the offer shock or the changes of the prices in the foreign markets. What can be said about a situation like this is that for Albania the regime of inflation targeting would be more effective than the regime of monetary targeting. 


\section{Monetary Policy and the regime of inflation targeting in Albania}

Our country may be considered successful in the war against inflation. In 1992 the inflation rate reached the level of $237 \%$, while in 1996 it reached the level of 6\%. In 1997 because of the fall of the pyramidal schemes, inflation reached high levels, however it was managed successfully. Mc Neilly (1998) attributes the success of Albania in reaching low inflation to the early liberalization of the prices, accompanied with the supporting policies to increase competition and the early increase of the aggregating offer of goods and services, besides a limiting monetary policy followed by the Bank of Albania. The direction of the monetary policy is achieved via the use of direct instruments and the use of the indirect ones. Until the middle of the year 1995, the money offer (M3) was controlled via the direct instrument "Mortgage ceilings". From 1995, the control of money quantity was done via the interest norms of the bank deposits. In 1999, the Bank of Albania removed the mortgage ceilings for the second-level banks. Meanwhile, if these banks had a report of the bad mortgages towards the mortgage total over $20 \%$, they were not permitted to give new mortgages. In 2000 (in the second part of the year) the Bank of Albania did not use the direct instruments for the application of the monetary policy, but the indirect ones. At the moment, the Central Bank is influencing on the interest norms via the open market operations in treasury bills (REPO). In 2012, the average annual inflation resulted to be $2 \%$. The objective of the Bank of Albania is to take inflation to the annual average level of $3 \%$ for an average-term period. The reasons for a low inflation level are related to the existence of a weak request during this period, the negative production gap, the stable exchange, the anchored inflation tendencies, the low increase of the input costs, the low level of the profit margins by the businesses. If we could do an assessment of the monetary policy based on the inflation, it would be considered a successful policy. However, the control of money offer cannot be considered the "best" tool for the inflation control under the conditions when several requirements should be fulfilled, such as: transparency, credibility and stability. Hadëri and Mytkolli, Kunst and Luniku (1998), Kolasi, Çeliku and Harshova, 2001, have reached at the conclusion that money connection to inflation is weak. This means that in Albania inflation depends on other macroeconomic factors except for the control of monetary offer. Exchange rate is among the most important factors that influence on the inflation pressures (Hadëri 1999). The exchange rate influences on the inflation rate in three ways: (i) in the consumption of the import goods, in such a way that the underestimation of the domestic currency will increase the price of the import goods influencing even on the imported inflation increase; (ii) in the net exports of a country; (iii) in the investment level. As these three elements are part of the aggregate request, and the exchange rate change will influence on these components, even the country aggregate request will change and consequently even the inflation pressures in the country. Except for the exchange rate, even the fiscal policy has a significant importance in the inflation pressures of the country. Based on the abovementioned reasons, that the inflation does not depend only on the monetary factors, the Bank of Albania did not have the monetary indicators as its main objective, but it intended to keep the inflation under control. To achieve this goal, in its strategic document "Average-term development plan of the Bank of Albania 2003-2005", it was written that: "... suitable regime is considered the inflation targeting regime ...". IT regime results to be successful if it is applied in a surrounding with a stable macroeconomic and institutional stability, and if it is understood and welcomed by the economic agents and subjects.

Table 1. Main macroeconomic indicators

\begin{tabular}{|c|c|c|c|c|c|}
\hline & 2008 & 2009 & 2010 & 2011 & 2012 \\
\hline \multicolumn{6}{|c|}{ Inflation (year over year, period average) } \\
\hline Basic inflation (in \%) & 2.8 & 1.4 & 1.7 & 3 & 1.5 \\
\hline Total inflation (in \%) & 3.4 & 2.3 & 3.6 & 3.5 & 2 \\
\hline \multicolumn{6}{|l|}{ Economic increase } \\
\hline Real increase of GDP $(\%)$ & 7.5 & 3.3 & 3.81 & 3 & 1.62 \\
\hline $\begin{array}{l}\text { GDP (with current prices, in } \\
\text { million lek) }\end{array}$ & $1,089,293$ & $1,148,082$ & $1,222,462$ & NA & NA \\
\hline
\end{tabular}




\begin{tabular}{|c|c|c|c|c|c|}
\hline \multicolumn{6}{|l|}{ Job market } \\
\hline $\begin{array}{l}\text { Number of the employees (in } \\
\text { thousands) }\end{array}$ & 974.1 & 899.3 & 916.9 & 928 & 922.52 \\
\hline Unemployment rate & 12.7 & 13.7 & 13.5 & 13.3 & 13.32 \\
\hline Fiscal sector & & & & & \\
\hline $\begin{array}{l}\text { Budget balance (with the grants, in } \\
\% \text { of GDP) }\end{array}$ & -5.5 & -7 & -3.1 & -3.5 & -3.4 \\
\hline Public debt (in \% of GDP) & 54.7 & 59.4 & 58.5 & 59.4 & 60.92 \\
\hline Budget incomes (in \% of GDP) & 26.7 & 26 & 26.6 & 25.4 & 24.4 \\
\hline $\begin{array}{l}\text { Budget expenses (in \% of the GDp } \\
\text { Foreign sector }\end{array}$ & 32.3 & 33 & 29.7 & 28.9 & 27.8 \\
\hline Current account (in $\%$ of GDP) & -15.6 & -15.3 & -11.5 & -12.1 & -9.22 \\
\hline Goods imports (in \% of GDP) & 37.7 & 35.1 & 36.7 & 39.3 & 35.82 \\
\hline Goods exports (in \% GDP) & 10.3 & 8.6 & 13.2 & 15.2 & 15.42 \\
\hline $\begin{array}{l}\text { Foreign Direct Investments (in \% of } \\
\text { GDP) }\end{array}$ & 7.5 & 8.2 & 8.9 & 8.1 & 7.62 \\
\hline $\begin{array}{l}\text { Tools of currency reserves (million } \\
\text { euro, end of the period) }\end{array}$ & 1,675 & 1,646 & 1,912 & 1,912 & $20,242.00$ \\
\hline Monetary and financial sector & & & & & \\
\hline REPO-s norm (end of the period) & 6.25 & 5.25 & 5 & 4.75 & 4 \\
\hline $\begin{array}{l}\text { Aggregate M3 (annual increase, } \\
\text { end of the period) }\end{array}$ & 7.7 & 6.8 & 12.5 & 9.2 & 5 \\
\hline $\begin{array}{l}\text { Mortgage for the private sector } \\
\text { (annual increase, end of the period) }\end{array}$ & 32.2 & 11.7 & 10.6 & 10.4 & 1.5 \\
\hline 12-month yield (annual average) & 8.16 & 9.17 & 7.98 & 7.34 & 7.03 \\
\hline Average exchange rate, lek/USD & 83.9 & 95 & 103.9 & 100.84 & 108.24 \\
\hline Average exchange rate, lek/EUR & 122.8 & 132.1 & 137.8 & 140.34 & 139.02 \\
\hline Effective nominal rate, NEER & 99.7 & 107.1 & 113.4 & 113.8 & 113.69 \\
\hline
\end{tabular}

Source: Bank of Albania

In connection to the macroeconomic developments in the country, we can say that during the year 2012 the country was characterized by a positive economic increase but at lower levels than the previous year, mainly because of the low aggregate request, the low level of the mortgage and the existence of a high insecurity. The unemployment level remained at the level of $13.3 \%$. This figure is the same with the one of the previous year, which is a significant indicator with regard to the declining effect it has got on the salaries and the other job costs. The exchange rate was relatively stable, which is a trend that had a positive impact on the inflation level within the objective defined by the Bank of Albania. The financial market was influenced even by other international factors which were connected with a high insecurity even because of the unpredictable fluctuations of the international financial markets. Thus, during the year 2012, the Bank of Albania took some measures for the decrease of the base interes t rate. These measures influenced on the improvement of the liquidity situation in the country and even on the decrease of the monetary aggregate M3. The other group of the macroeconomic policies, fiscal policy, had a reducing impact in the level of the budget deficit in report with GDP - compared to 2011. The decrease of the budget deficit mostly came as a result of the increase of the expenses on public investments. With regard to the foreign sector, we can notice a decrease in the current account deficit because of the foreign and domestic request. Financial and capital account marked an overflow of 607.4 million euro in 2012, which ensured the financing of the current deficit in the measure of $90.5 \%$. The biggest income flows (obligations) had the form of foreign direct investments. The net foreign direct investments achieved the value of 541.4 million euro, which is a figure about $22 \%$ higher than in 2011. The greatest part of the FDI has entered in the form of the securities (shares) and in the form of the reinvestments of the investment profits.

\subsection{Inflation Targeting. Advantages and disadvantages in Albania}

As the inflation is influenced by several factors, the use of the monetary regime cannot be optimal for 
countries like Albania. Therefore, in 2005 the Bank of Albania decided to pass to the IT regime for an average-term period. According to Cukierman and Liviatan. 1992; Svensson 1997, IT is based on the idea that the best mediate objective of the monetary policy, which targets the inflation control, is the prediction of the inflation itself.

\section{1.a. The favourable conditions for the Inflation adaption in Albania}

The application of the IT needs an environment with a stabilized inflation for a period of at least 2-3 years. During 2011-2012, inflation did not go beyond the level of $4 \%$ in an annual average level. Another important precondition for the application of this regime is the execution of a flexible exchange rate regime. From the second period of the year 1992 and in continuation, the Bank of Albania follows the policy of the free exchange rate, where the price is defined by the market. From 1992, the Bank of Albania has followed a policy of the exchange rate, which implies a non-intervention of the Bank in the market. In its currency policy, the Bank of Albania predicts to interfere in the market only when speculations are noticed in the market, which may be accompanied with considerable fluctuations of the currency far from the tendency which showed up over the years. The successful application of this regime requires a budget deficit of $3 \%$ in report to GDP. The preservation of the budget deficit under the level of $3 \%$ in report with the domestic gross product and the prohibition by law of the budget deficit financing by the Bank of Albania created facilities for the application of the Inflation Targeting regime. Another favouring factor for the application of the IT is connected with the legal and institutional framework of the Bank of Albania. The current law of this institution guarantees a high level of legal, economic and operational independence. With regard to the transparency level, attempts have been made to increase the transparency level in order to make the policies followed by the Central Bank as understandable for the public as possible.

\section{1.b. Problems caused by the Inflation Targeting adaption}

As it was mentioned even in the above paragraphs, the law guarantees to the Bank of Albania a high independence level, but is this a real independence? At this point, it is important to achieve the full elimination of the budget deficit financing by the Central Bank. This measure would give to the Bank the opportunity to avoid the government interventions in the application of the monetary policy. The successful adaptation of the IT regime requires that the public understand the mechanism of the monetary policy transmission, the inflation causes, the way how the Albanian economy functions generally and the improvement of the economic statistical data. These is sues may be managed even by the Central Bank. However, there are several factors which are not under the control of the Bank, such as: the prices controlby the government, the fiscal discipline, the decrease of the emigrants' remittances, financial system stability, etc. With regard to the prices control by the government, we can say that it would be damaging firstly for the trade economy functioning. The fiscal discipline is an important factor for the successful application of the IT, as a fiscal policy which would increase the money quantity in circulation, would further increase the inflation pressures. The progress of the financial system is another important component for the monetary policy. The development level of the Albanian financial system is not enough to have an effective monetary policy. This happens because the stock market and the money trades do not function. While, with regard to the competitiveness level of the second-level banks, we can say it is at a satisfactory level considering the number of the ones which operate in the market, their quality and the quantity of the services they offer to the client.

\section{1.c. Other alternative regimes}

Other alternative regimes which were mentioned even above are the specification of the exchange rate "just do it". In Albania the major part of the goods and the services is ensured via the import. This makes us think that this regime would be suitable for our country. However, it is considered unsuitable because: (i) there should be sufficient monetary reserves at any moment to keep a stable exchange rate; (ii) the risk for an overprice of the real exchange rate. "Just do it" regime was excluded as an opportunity as the Bank of Albania does not have the same reputation as the FED. 


\section{Conclusions}

- Even though the monetary regime has kept the inflation at specific levels, it may not secure this stability even in the future.

- The use of the alternative regimes, as the one of the Inflation Targeting, would be a good alternative to transmit the efficiency of the monetary policy, even though there are some problems.

- The successful adaptation of the Inflation Targeting requires the accomplishment of several conditions which are always easy to be achieved.

\section{References}

1 Estrella, A. and Mishkin, F. (1997) "Is there a role for monetary aggregates in the conduct of monetary policy?” Journal of Monetary Economics, Vol.40, pp. 279-304.

2 Cukierman, A. \& Liviatan, N. (1992) “ The Dynamic of Optimal Gradual Stabilisation." World Bank Economic Review, Vol. 6, pp. 439-458.

3 Svenson L.E.O. (1997) “Inflation Forecast Targeting: Implementing and Monitoring Inflation Targets.” NBER Working Paper No. 5797

4 Average-term development plan of the Bank of Albania (2003-2005), page 27

5 Cani Shkëlqim, Baleta Teuta (1999) Element of teh Independece of teh Central Bank. Bank of Albania: How independent is it?, discussion paper, no. 1/99, September 1999, Bank of Albania Publication

6 Clausen Jens R. and Meier Carsten-Patrick, Did the BundesbankFollow a Taylor Rule? An Analys is Based on Real-Time Data, IWP Discussion Paper No. 2003/2 August 2003

7 Erjon Luçi and Fatos Ibrahimi: "A review of the Monetary Targeting in Albania with some orientations for the future", the fifth conference of the Bank of Albania: Central Banking in the Inegration Time, 24-25 March 2005

8 Bank of Albania, Law no. 8269, on 23.12.97 "For the Bank of Albania"

9 Bank of Albania, Annual Reports (2004, 2005, 2006, 2007, 2008,2009, 2010, 2011, 2012)

10 Hadëri S., Papagzyos H., Sanfey P., Talka M., " Inflation and stabilization in Albania” Postcomunist Economies, vol II, 1999. 